\title{
What future for European seals now the epidemic is over?
}

\author{
Mark Simmonds
}

\begin{abstract}
The European seal epidemic killed approximately 60 per cent of harbour or common seals Phoca vitulina in the colonies of the Wadden Sea, Kattegat-Skagerrak and the Norfolk Wash. High mortality was also observed elsewhere. The die-off peaked in 1988 and few affected seals have been reported subsequently. But what of the future? Is the marine environment still able to support healthy seal populations; is there enough suitable habitat for them; is there enough food; what is the impact of pollution on them; and why has no new legislation been implemented to protect them?
\end{abstract}

\section{The impact of the epidemic}

The first signs of the epidemic (or more correctly, the epizootic) were seen in harbour seals Phoca vitulina in April 1988 around the Danish island of Anholt in the Kattegat (Dietz et al., 1989). Aborted pups and then seals of all ages were washed ashore. Dead seals were soon also reported from the Swedish coast and then the Wadden Sea. In the early summer, the epidemic spread to the coast of Norway and seals in the south-western end of the Baltic were also affected. In August, the first official reports were noted of problems in English (Norfolk) stocks, closely followed by reports from the Irish Sea and Scotland. However, some colonies initially seemed unaffected, including those far off in the Baltic and Iceland and the rather scattered harbour seals of northern Norway.

Estimating regional seal mortality is difficult. In parts of the Wadden Sea, for example, the number of dead harbour seals exceeded previous estimates of the total population (Dietz et al., 1989). However, it is a fact that across Europe some 18,000 harbour seals died.

The significance of the epidemic for grey seals Halichoerus grypus remains obscure. There is evidence to show that some became infected and in 1988 several hundred were found dead in the UK (Harwood, 1990). However, the nature of the Scottish and Norwegian coastlines, where a significant pro- portion of the world's population of grey seals lives, makes any observations from these areas difficult to interpret. The human population in these regions is comparatively small and scattered and so the reporting of dead seals is less likely. Furthermore, the terrain is largely rocky with weed-strewn shores making bodies difficult to spot and this is exacerbated by strong tides and currents, which can carry corpses out to sea. This may have lead to substantial underestimation of seal mortality (Reijnders, 1989). However, it has been reported that the number of grey seal pups born at the end of 1988 fell by some 12 per cent (Harwood, 1990). Whether this was because of direct effects of the virus on them or on their parents remains to be shown.

Such a dramatic mass mortality caused tremendous public concern. In the spring and summer, as successive reports from the Wadden Sea indicated mortalities of 80, then 90 and finally 100 per cent, fears were raised that harbour seals in Europe were facing extinction. Before the epidemic reached the UK, an Emergency Working Group in London, organized jointly by Queen Mary College and Greenpeace, brought together European biologists, veterinary experts and toxicologists. They reviewed the evidence available (at that time, two types of virus, either a picorna virus or one of the herpes family, were suspected of being involved) and the scientists echoed the public's concern with respect to pollution. 


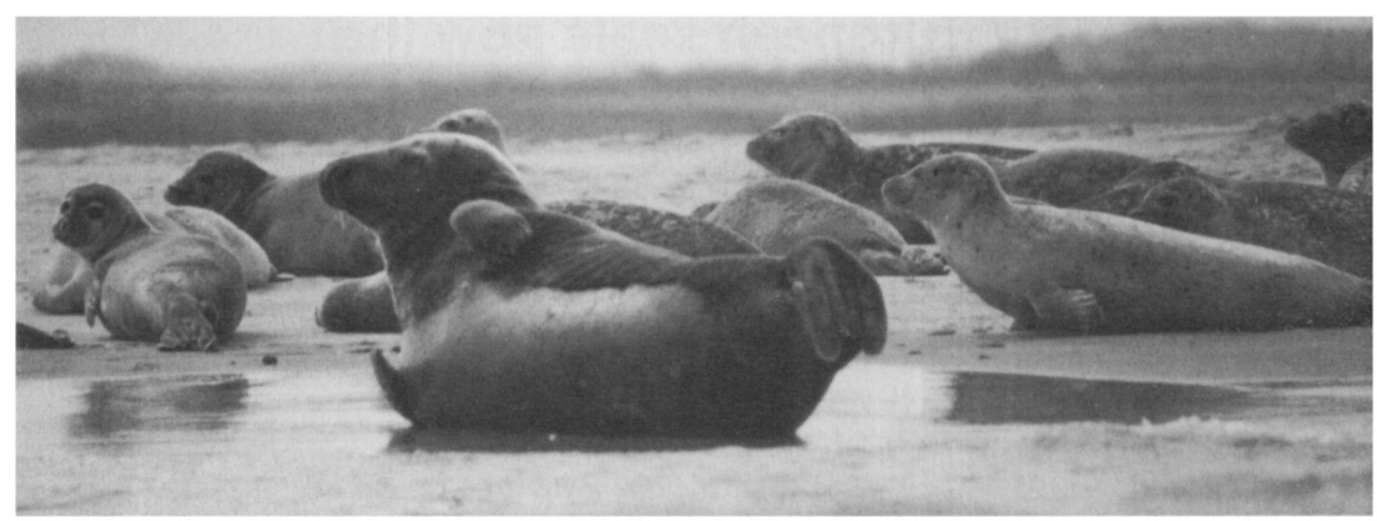

A grey seal in the foreground, with harbour seals behind, Blakeney Point, Norfolk (M. Simmonds).

They noted in their official statement that the action of persistent pollutants could not be excluded as an additional factor in the seal deaths, especially as the seals were known to be highly contaminated with pesticides and related compounds. The group also reported that the seal sanctuary at Pieterburen in The Netherlands had, over the last 5 years, noted a clear increase in both the numbers of sick seals being received and the severity of their diseases.

Shortly after this meeting the Royal Society for the Prevention of Cruelty to Animals and Greenpeace established the Seal Assessment Unit at Docking in Norfolk, UK. This was close to Europe's main harbour seal colony and the unit was designed to research the epidemic and, if possible, help the stricken seals, which soon filled its isolation units. Seals that died were autopsied and samples sent for further examination to laboratories across Europe.

Clinical and post-mortem investigations showed the disease to have great similarity to canine distemper virus (Bergman et al., 1988). This is a virus of the highly pathogenic morbillivirus family, which also includes measles and rinderpest. The seals typically developed pneumonia-like symptoms with characteristic discharges from the nose, mouth and eyes. This often culminated in massive loss of air into the thoracic cavity from consolidated and leaky lungs, an effect that trapped the seals at the water surface unable to dive or feed and at the mercy of scavengers. Many must have had long lingering deaths as indicated by the greatly reduced depth of blubber on washedup corpses. A few also showed neurological symptoms-usually just before death.

Dutch and British scientists have since characterized phocine distemper virus (PDV) (e.g. Osterhaus and Vedder, 1988), which now seems to be a morbillivirus new to science. Blood samples from North Sea harbour and grey seals suggest that prior to 1988 these seals had not been infected by morbilliviruses (Harwood and Grenfell, 1990), although there is some evidence that this may not be the case. However, morbillivirus antibodies have been detected in samples taken from Greenland harp seals Phoca groenlandica and ringed seals Phoca hispida before the European epidemic. Furthermore, in 1987, many of the endemic seals Phoca sibirica in Lake Baikal in Siberia were killed by a morbillivirus (although perhaps distinct from PDV) and recent research shows that bottlenose dolphins and harbour porpoises are also susceptible to morbillivirus infection (Kennedy et al., 1988; Geraci, 1989). Thus, infection by the same or similar viruses may actually be common in marine mammals.

A second wave of the epidemic was anticipated by some scientists in the summer of 1989, when seals would again be hauled out and concentrated together (Harwood et al., 1989) but there was little sign of a resurgence. The Docking Seal Assessment Unit rescued many stranded pups but, despite suspicious reports earlier in the year, they were not infected by the morbillivirus. There were, 


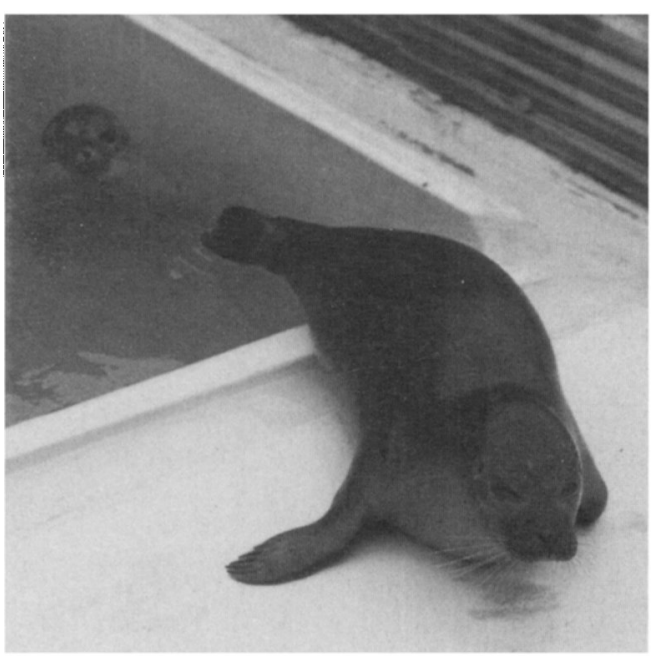

Recovering harbour seal pups in a pool at the Seal Assessment Unit (M. Simmonds).

however, many sick pups reported in Orkney and PDV was diagnosed from some (R. Flett, pers. comm.). In autumn 1989 a number of seals were found sick and dead in northern Norway, which had previously appeared unaffected by the virus. Investigations have since indicated that these were also infected with PDV (Krogsrud et al., 1990).

Blood tests indicate that about half of the remaining UK harbour seals have not developed an antibody response to morbillivirus (Harwood et al., 1989). The youngest age classes may not have yet come into contact with the virus and, as they make up some 40 per cent of the population, some scientists believe that there is a substantial risk of a recurrence in the near future (Harwood and Grenfell, 1990). The risk will increase with time as the proportion and density of susceptible animals increase.

\section{Is pollution involved?}

Evidence concerning the role of pollution is likely to be circumstantial. One such piece may be implicit in the pattern of death. Mortality around the UK seems to vary-high off Norfolk (as elsewhere in Europe), comparatively low around Scotland, and intermediate in Strangford Lough, Ireland (Harwood, 1990). These estimates of mortality have to be viewed cautiously as little detailed information of seal numbers post-epidemic has yet

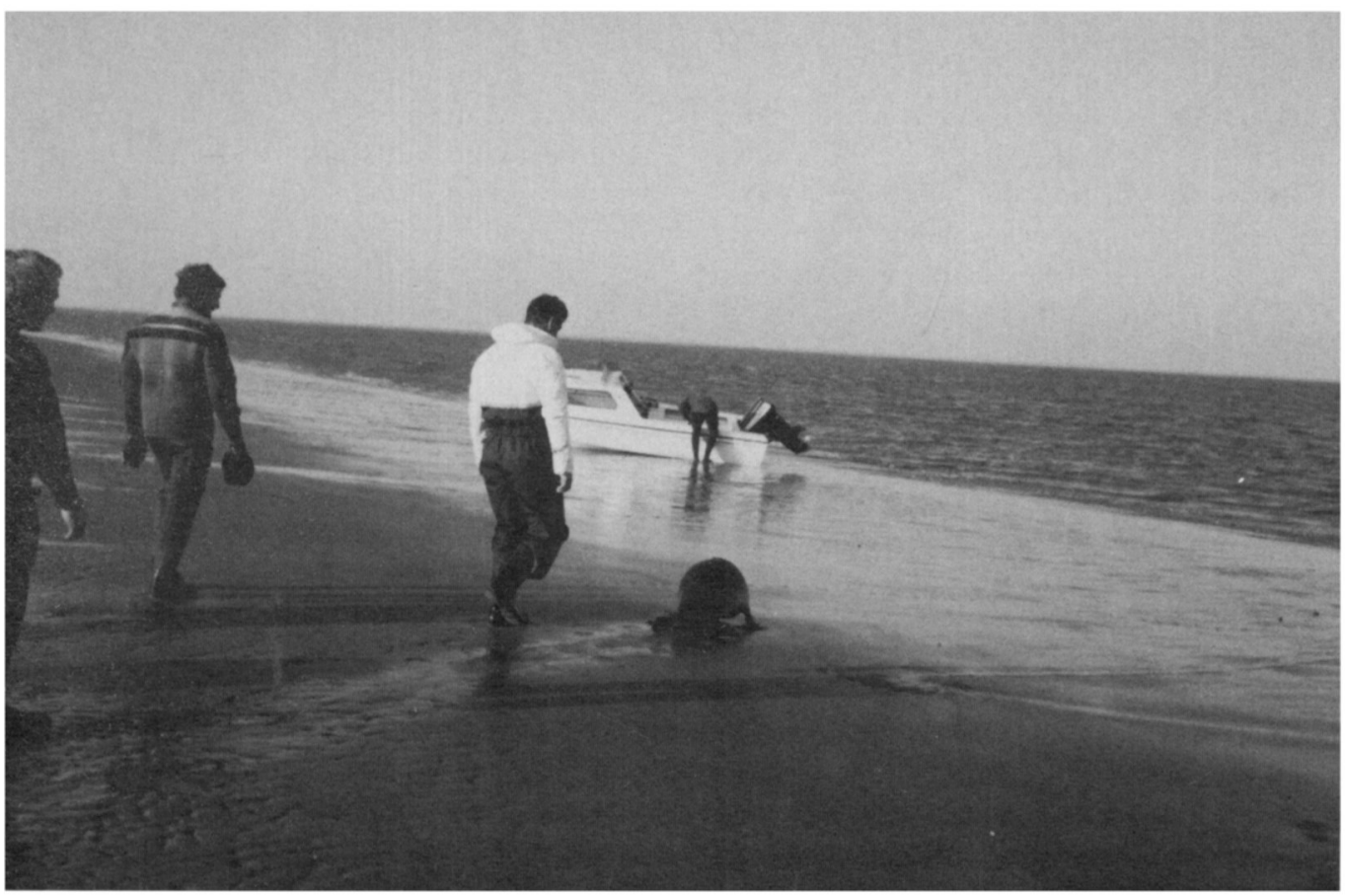

The release of a seal from the Seal Assessment Unit back into the Wash (M. Simmonds). 
been published. Even so, some authorities have noted that Scottish waters would be expected to be less polluted than in southern England or elsewhere in Europe, where higher mortality occurred. Is there a correlation?

Does such a theory also take into account secondary pathogens? Most of the seals were not killed by PDV itself but by secondary infections (particularly of the lungs) facilitated by the primary morbillivirus infection. This brings into question possible regional differences in these pathogens, such as opportunistic bacteria, the presence of which could be affected by temperature, the presence of human sewage in the water or other factors.

Generally, evidence for the harmful impact of persistent contaminants (pesticides, like DDT, and other compounds such as PCBs) on wildlife comes from laboratory studies on a range of animals. Reproductive failure and the suppression of the immune system are common results of exposure to such pollutants (see Safe, 1984). In the wild, the presence of DDT and PCBs has been correlated with reproductive failure in southern Wadden Sea harbour seals and gross blockages of the uterus in Baltic Sea seals (see Reijnders, 1980). The failure of these two stocks to recover after the cessation of hunting in the 1960s has been widely attributed to this kind of reproductive impairment. Since the discovery of uterine occlusions in Baltic seals almost all seal researchers have been searching intensively for their presence. They have recently been found in Liverpool Bay grey seals (Baker, 1989) the first convincing evidence from anywhere else in Europe. There is also experimental evidence indicating that PCB-contaminated fish cause immunosuppression in harbour seals (Brouwer et al., 1989).

Many other factors could have been important in the outbreak and spread of the epidemic. These include the overall status and size of the seal populations, the availability of food and the climatological and oceanographic conditions prevalent at the time. Eis (1989) pointed out the need, in principle, to assume a multifactorial aetiology in the case of viral diseases. Lavigne and Schmitz (1990) have observed a correlation between past seal mass mortalities and unseasonably warm temperatures linked with high seal densities. The implications of global warming for seals could, therefore, be severe and might include more frequent epizootics as well as loss of their haul-out sites because of rising sea levels.

\section{Other threats to European seals}

Other factors adversely affecting seal stocks include hunting, organized culls, food shortages (caused by overfishing) and entanglement in fishing nets.

Fishermen in many areas blame seals for the depressed state of fish stocks. In Norway harp seals are scapegoats for the results of overfishing in the Barents Sea. This has become the justification for the national commercial seal hunt. Scottish fishermen have also recently called for a cull of seals. Both situations stem from an inclination to blame seals when fishing becomes difficult. However, the fact that seals eat fish is not proof that they either control or significantly reduce fish stocks. Such a link has never been scientifically proven (see Earle, 1989). Fishermen would be better advised to admit that fishing has been too intense and to reduce their fishing effort.

Not only are there frequent calls for largescale seal culls but seals are also shot to protect fish stocks. This may be especially significant around Scottish fish farms. Salmon farmers, when faced with the choice of paying for adequate anti-predator nets to keep seals and birds away, may prefer the cheaper option of shooting them. Thus, a multi-million pound industry may kill seals and also shags, cormorants and even otters, to save a few hundred pounds. Interviews with fish farmers, fishermen, river bailiffs and others suggest that thousands may be shot in British waters every year (Ross, 1988; R. Galvin pers. comm.).

While the depletion of fish stocks resulting from overfishing obviously causes serious economic problems for the fishermen, it may well be a matter of life or death for seals and other marine animals. In the Barents Sea, the stocks of herring and capelin have collapsed, and cod 
and prawn stocks are also becoming dangerously low. This may have created difficulties for harp seals and many tens of thousands have drowned in nets in recent years. This has been attributed most frequently to their seeking alternative food sources, especially as many of the dead seals are exceptionally thin. The sand eel fishery around the Shetland Isles has also recently collapsed (although the factors concerned are still under investigation) and local seabirds dependent on these fish to rear their chicks have suffered breeding failures (Avery and Green, 1989). There are colonies of grey seals in the area and they could also be experiencing problems in finding food. Sand eels have been found to make up more than 60 per cent of the grey seal diet (Harwood and Croxall, 1988).

Another problem stems from certain types of fishing gear. Coastal gill nets annually entangle and kill countless thousands of seals around the world and the same sort of equipment is used in Europe. This static gear seems to be extremely difficult for seals to detect and avoid. Of 5950 grey seals tagged in the Farne Islands since the early 1960 s, some 130 have been recovered from fishing gear and a similar observation has been made on tagged seals around the Orkney Islands (Northridge, 1988). However, the numbers known to have been killed in this fashion are only a minimum estimate as very few of the seals entangled would ever be reported. Seals ensnared in all types of fishing gear were included in these figures but inshore gill and trammel nets were regarded as the main causes of mortality. A single fishing boat, albeit in an experimental tangle-net fishery off Scotland, was found to catch 107 seals in a 2-month trial.

Furthermore, fishing nets that are discarded or lost continue to fish indiscriminately. Similarly, packing bands, straps and other non-degradable plastic waste may trap animals. Seals caught in this manner may drown immediately, or, as they grow, acquire an ever tightening girdle or suffocating noose, which may ultimately kill them.

Considering the number of threats currently faced by North Sea and Irish Sea seals, their future status is far from assured.

\section{Existing legislation}

Seal protection in the North Sea states is regulated by a double tier of international conventions and national legislation. However, it is striking that the governments of some countries still allow seals to be killed, while others have banned any form of hunt and actively support the rehabilitation of sick seals and abandoned pups.

Common and grey seals are listed in Appendix III of the Bern Convention on the Conservation of European Wildlife and Natural Habitats. This is the lowest grade of protection and does not prohibit killing; it only regulates exploitation. These regulations are far too weak to provide proper protection for seals. For example, they do not deal with incidental catches of seals in fishing gear and those concerning habitat protection are somewhat unclear.

Seals can still be legally shot in several North Sea countries. In the UK the Conservation of Seals Act 1970 does not prohibit either species of seal being shot in the 9 months of the year outside pup-weaning time. After the seal epidemic, the British Government provisionally extended this closed season to the whole year. However, this does not include grey seals in Scottish waters and the measure is only temporary. Exceptions are also made in the name of the prevention of damage to fisheries, so any seal found near a fish farm or fishing gear can be legally shot.

By contrast, the three Wadden Sea countries recently took an important step in concluding an agreement (under the Bonn Convention) to protect harbour seals in the Wadden Sea. The killing and taking of seals is forbidden, and the countries committed themselves to prevent disturbance and pollution of resting and breeding areas. The three states (in November 1988) adopted an immediate plan of action.

However, when Ministers from all the North Sea states assembled in March 1990, at the Third International Conference on the Protection of the North Sea, they did not agree any measures to protect the depleted seal stocks. They acknowledged the need to further research the factors that caused the epi- 
demic. There is little doubt that this is necessary but there seems to be an increasing tendency on the part of politicians to quote the need for more research as an alternative to implementing relevant conservation legislation.

\section{Conclusion}

Current attention must focus on the future prospects for North and Irish Sea seals and they must be given as much help in recovery as possible. Whatever the reasons for the epidemic, most stocks are now known to have been severely reduced and a question mark hangs over the future of all European seals. Furthermore, there is little doubt that pollution levels are sufficiently high in some areas that seal reproduction is impaired. Perhaps other countries could adopt the approach of the Wadden Sea states, by recognizing the threats and affording the seals sensible protection?

\section{Acknowledgments}

I am very grateful to Michael Earle, Jikkie Jonkman, Ros Flett and Drs Nicky Kemp, Robert Galvin and Paul Johnston for their help in the preparation of this paper.

\section{References}

Avery, M. and Green, R. 1989. Not enough fish in the sea. New Scientist, 22 July, 28-29.

Baker, J.R. 1989. Pollution-associated uterine lesions in grey seals from the Liverpool Bay area of the Irish Sea. The Veterinary Record, 9, 303.

Bergman, A., Harkonen, T., Klingeborn, B. and Olsson, M. 1988. Valpsjuka hos sal. Viltnytt, 26, 16-23.

Brouwer, A., Reijnders, P.J.H. and Koeman, J.H. 1989. Polychlorinated biphenyl (PCB)-contaminated fish induced vitamin $A$ and thyroid hormone deficiency in the common seal (Phoca vitulina). Aquatic Toxicology, 15, 99-106.

Dietz, R., Heide-Jorgensen, M-P. and Harkonen, T. 1989. Mass deaths of harbor seals (Phoca vitulina) in Europe. Ambio, 18, 258-264.

Earle, M. 1989. Harp seals and the Northern Cod Stock: Brief to the Northern Cod Review Panel. 20
October $1989,9 \mathrm{pp}$.

Eis, D. 1989. Simplification in the etiology of recent seal deaths. Ambio, 18, 144.

Geraci, 1989. Clinical investigation of the 1987-88 mass mortality of bottlenose dolphins along the US central and South Atlantic Coast. Final Report to NMFS, USNONR and MMC, $62 \mathrm{pp}$.

Harwood, J. 1990. What have we learned from the 1988 seal epidemic? Biologist, 37, 7-8.

Harwood, J., Carter, S.D., Hughes, D.E., Bell, S.C., Baker, J.R. and Cornwell, H.J.C. 1989. Seal disease predictions. Nature, 339, 670 .

Harwood, J. and Croxall, J.P. 1988. The assessment of competition between seals and commercial fisheries in the North Sea and the Atlantic. Marine Mammal Science , 4, 13-33.

Harwood, J. and Grenfell, B. 1990. Long term risks of recurrent seal plagues. Marine Pollution Bulletin, 21, 284-287.

Kennedy, S., Smyth, J.A., Cush, P.F., McCullough, S.J., Allan, G.M. and McQuaid, S. 1988. Viral distemper now found in porpoises. Nature, 336, 21.

Krogsrud, J., Evensen, O., Holt, G., Hoie, S. and Markussen, N.H. 1990. Seal distemper in Norway in 1988 and 1989. The Veterinary Record, 126, $460-461$.

Lavigne, D.M. and Schmitz, O.J. 1990. Global warming and increasing population densities: a perception for seal plagues. Marine Pollution Bulletin, 21, 280-284.

Northridge, S. 1988. Marine Mammals and Fisheries: A Study of Conflicts with Fishing Gear in British Waters. Report to the Wildlife Link Seals Group. 140pp.

Osterhaus, A.D.M.E and Vedder, E.J. 1988. Identification of a virus causing recent seal deaths. Nature, 335, 20.

Reijnders, P.J.H. 1980. Organochlorine and heavy metal residues in harbour seals from the Wadden Sea and their possible effects on reproduction. Netherlands Journal of Sea Research, 14, 30-65.

Reijnders, P.J.H. (ed) 1989. Proceedings of International Workshop Seal Disease Epidemic.

Ross, A. 1988. Controlling nature's predators on fish farms. A report for the Marine Conservation Society. $96 \mathrm{pp}$.

Safe, S. 1984. Polychlorinated biphenyls (PCBs) and polybrominated biphenyls (PBBs): biochemistry, toxicology and mechanism of action. CRC Critical Review of Toxicology, 13, 319-395.

Mark Simmonds, Greenpeace Research Associate, School of Biological Sciences, Queen Mary and Westfield College, University of London, Mile End Road, London E1 4NS, UK. 